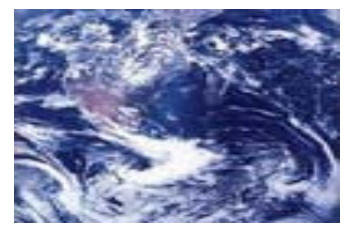

\title{
From Cognitive Landscapes to Digital Hyperscapes
}

\author{
José Bidarra \\ Universidade Aberta, Portugal
}

\section{Ana Dias}

Interface da Universidade do Minho, Portugal

\begin{abstract}
The widespread diffusion of e-Learning in organizations has encouraged the discovery of more effective ways for conveying digital information to learners, for instance, via the commonly called Learning Management Systems (LMS). A problem that we have identified is that cognitive variables and pedagogical processes are rarely taken into consideration and sometimes are confused with the mere use by learners of "diversified" hypermedia resources. Within the context of widespread dissemination of multimedia content that has followed the emergence of massive information resources, we discuss the need for more powerful and effective learner-centered tools capable of handling all kinds of design configurations and learning objects.
\end{abstract}

Keywords: cognitive profiles; learning styles; mind mapping; multimedia and hypermedia content; hyperscapes; e-Learning; learning objects; Learning Management Systems (LMS)

\section{Introduction}

In the development of educational products and systems, learner variables are often neglected. It is common to find the emphasis on the multimedia technology itself. One must ask: When eLearning solutions are applied, why are cognitive landscapes not taken seriously? In our view, any learning system should address the issue of different individual learning abilities. However, regardless of the interaction potential they offer, cognitive representations may vary so widely that a single system will not be able to cope with such variation (Rogers and Scaife 1997). Aspects such as learning ability, developmental issues, memory organization and capacity, and the nature of cognitive representation are crucial. There is also some evidence (Hay et al., 1994) that educational technology affects students differently. While it works effectively for some, it fails for others. The same is true for teachers and tutors. These research issues have yet to be resolved through more in-depth observation and evaluation of subjects that come into contact with e-Learning systems. 
While those researchers working at the frontiers of knowledge might disagree about how the human mind works, there seems to be agreement on some basic principles (Kahneman, Slovic, and Tversky, 1982). According to Kahneman et al., the mind:

- Is an inference machine that actively imposes order on highly ambiguous situations

- Works to keep internal core beliefs consistent and unchallenged and thus will deny, distort or ignore signals that contradict core beliefs

- Prefers simplicity

- Is constrained by reality in important ways (effect of the circumstances)

- Prefers stable and enduring relationships among its core beliefs

In other words, where nature is ambiguous, people tend to develop strong beliefs and act upon them. Reflective practice and critical thinking also match this strategy. People tend to simplify complexity and make the inconsistent seem consistent. These characteristics have strong implications for the design of multimedia and hypermedia learning materials.

Our mental processes make rapid estimates of what information is valuable to notice and what can be treated as background - phenomenon that is extensively addressed by Gestalt Theory. Furthermore, when we look at a composition of images on a screen, the mind takes some of these images and creates something that fits existing mental schemas. In other words, we see every image we come across with theory-laden vision. Each and every one of us assigns meanings differently.

\section{Cognitive Profiles and Learning Styles}

Perhaps because mental schemes are so important and so necessary for orderly interaction with others, people are reluctant to change them. In fact, people tend to hold on to that self-achieved order and often fight to retain their individual "mind maps.” Because of this human tendency, we argue that in the design of multimedia and hypermedia learning materials, the input of individual cognitive preference naturally becomes an important factor.

Although it is a historically situated approach, four types of "cognitive profiles" identified by Jung (1960) are still worth revisiting:

1. Intuitive (integrates patterns, possibilities, ideas)

2. Feeler (is concerned mainly about people and life)

3. Thinker (focuses on cause and effect)

4. Sensor (is concerned with activities and events)

Another quadrilogy that we should refer to has been suggested by Uys (1998), that was based on Kolb's Model of Experiential Learning (1984), and acknowledges that every student has a mixture of four basic "learning styles" (see Figure 1): 
1. Reflector: This student learns best by reflective observation. Learners can be provided with appropriate exercises in course pages, and because a large proportion on the Web is asynchronous, this caters naturally to the needs of reflective students.

2. Pragmatist: This student learns best by engaging in practical applications. Practical exercises are assigned within a problem solving structure, with theoretical support of images and sound used to contextualize this student's learning experience.

3. Theorist: This student learns best by abstract conceptualization. As instructional pages of (information-giving) course material are readily available, relevant narrative modules can be easily digitized and made available in course pages.

4. Activist:This student learns best through activities and concrete experiences. The Web naturally lends itself to "discoveries" through the use of hyperlinks, and the main assets are its random navigation possibilities, a high-level of interactivity via email, message boards, and chat rooms, and, of course, the use of graphics, colors, sounds, and movement.

This differentiation suggested by Kolb (1984) stresses the need in a group or individual learning environment for flexible support of these styles, along with the possibility of effortless transition among them. Figure 1 shows the interactions among the relevant factors that make up the profiles within the Model of Experiential Learning.

Figure 1. Kolb's Learning Styles: Model of Experiential Learning (Kolb, 1984, p.58)

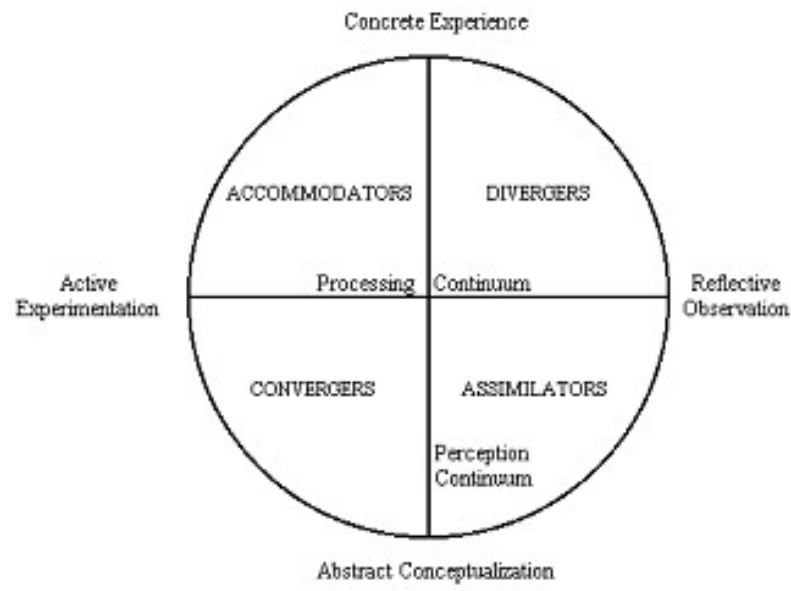

Cognitive characterizations are also important to define precise design concepts. More specifically, we are concerned with the issues designers need to consider in the development of interactive material. The "design concepts" outlined by Rogers and Scaife (1997) seem appropriate and relevant: 
- Explicitness and visibility: How may aspects that are more salient be displayed so they may be perceived and comprehended appropriately?

- Cognitive tracing: What are the best means to allow users to externally manipulate and make marks on different representations?

- Ease of production: How easy is it for the user to create different kinds of external representations - e.g., videos and animations?

- Combinability and modifiability: How may the system and users be enabled to combine hybrid representations - e.g., enabling animations and commentary to be constructed by the user, which could be appended to static representations?

These design concepts may be applied at a more detailed level by means of technical parameters such as the use of graphics, navigation aids, or types of media that may be implemented at the interface.

Redundant visual coding may be used to constrain the way information is interpreted. The coordination of elements and the cueing for certain aspects are also important. Regrettably, these tasks are often impossible to establish when we use commercial learning management software.

Design considerations cannot just rely on cognitive characterizations. The domain knowledge that needs to be learned by students has specific didactic characteristics that suggest how we may use different representations. For example, a chronological sequence of historical events may be illustrated by a series of relevant still images (e.g., paintings, photos, etc.); a poem may be more adequately illustrated by audio; and those learning from a physics experiment may benefit from slow motion video.

This issue is further complicated, because in many cases the formal representations are not merely explanation aids - they are an essential part of the domain of knowledge itself. Accordingly, we must differentiate between multiple representations as a system, and by this we mean representation systems such as, for instance, algebra plus graphs, and augmentations of a representational system - e.g., 3D images to show complex data.

\section{The Multimedia Experience}

Although it is desirable that learners be allowed and encouraged in a creative and purposive way to engage with multimedia and hypermedia materials, we must ensure they have access to learning experiences that both support and go beyond what may be achieved with print. To find out how this objective might be achieved, it is necessary to look in a broad perspective first at the user interface to distinguish between the mainly ergonomic aspects of access to multimedia materials and learners' subsequent interaction with them. According to Whalley (1997), "the extra resources involved in creating and accessing multimedia materials have to be justified in terms of improved learning, which is unlikely to result from simple issues such as the speed of information access, or to the large quantities of text that can be squeezed on to a CD” (p. 3). 
On the other hand, judging from the numerous CD-ROM and websites surveyed, a "more is more" philosophy has become pervasive. Many think that quantity and sophistication of multimedia information are important indicators of the value of educational materials. For example, adjectives such as "eye catching," "mind boggling," "powerful," and "dynamic” are used. However, based on observations of learners exploring multimedia materials (both on CDROM and the Web) we discovered that too much time is wasted by students wandering about, playing video clips and animations, whilst skimming through accompanying text or static diagrams. Rogers and Scaife (1997) reported a typical example that concerned the evaluation of a CD-ROM on design called "First Person," written by Don Norman, in which students consistently admitted to ignoring the text in search of clickable icons. Moreover, the selection of one icon would present an animated video of Don Norman explaining some aspect of design. According to Rogers and Scaife, rather than improve learning, this video introduced extra "noise" in the process. Students became quite passive and did not engage in active meaning making of their own. We can therefore conclude that many multimedia environments may, in fact, induce more dispersed and superficial learning.

Possibly relying on modular elements, an ideal prototype might comprise characteristics of a "microworld" - a highly interactive learning environment that is geared to open-ended problem solving. The environment should be self-contained and provide enough opportunities for multiple views and knowledge representations. A variety of questions could be posed and possible solutions could be explored in constructive ways via activities that engage individual learners. A natural starting point would be a workstation with a large color screen and a Windows operating system that divides the screen into logical parts used for different purposes. The use of Windows in precisely this manner is typical of many computer users/ students. For example, while a browser window shows live video, another window can provides simultaneous accompanying text annotation. We foresee the need to base any future solutions on robust platforms that support several channels of communication, as well as links between the multiple documents.

\section{Creating Digital Hyperscapes}

The knowledge construction process that learners engage in typically follows a specific learning profile, and therefore should be supported by appropriate multi-channel tools based on effective hypermedia technology. Hypermedia spaces - or hyperscapes - may be conceptually identified with huge networks that extend from hypermedia "pages" to vast knowledge "spaces" housed on the Web, where the latter tends to grow to a "landscape" dimension. However, hyperscapes are also cognitive artifacts that offer expressive power to authors, and work to support active learners as they develop knowledge paths relevant to their own aims and needs. As people make sense of the fragmentary information that surrounds them, they create branched structures of knowledge that diverge from a single node; usually there is something that triggers new thoughts, perhaps as a question or a new point of view. A key-element in our approach is the explicit introduction of "mind mapping support" in the construction, visualization, and navigation of complex knowledge structures (Gaines, 1995). This feature is currently not found in learning content management software. 
The construction of hyperscapes may be achieved through Mind Mapping ${ }^{\circledR}$, a popular technique invented (and copyrighted) by Tony Buzan in the UK. According to Buzan (1995) the mind mapping technique was developed for representing knowledge in layers that constitute branches or networks of ideas. Departing from a central word or concept, one can aggregate images, graphics, and dynamic media elements (e.g., audio and video) to the representation. The difference between a concept map and a mind map is that a mind map departs from one main concept, while a concept map may deal with several. Hyperscapes can rely on both kinds of maps, depending on the objectives and strategies we define for a given learning environment.

Mapping techniques were developed to represent knowledge in graphs that constitute networks of concepts (Gaines, 1995). Networks consist of nodes (points/ vertices) and links (arcs/ edges), where nodes represent concepts and links represent the relations between concepts. Concepts (and sometimes links) are labeled, and may be categorized: they may be simply associative, specified, or divided in categories such as causal or temporal relations. The resulting patterns of association and branching create fractal-type structures. Like clouds or trees, they form physical structures that do not possess a defined form; we can always describe other levels or scales of its structure, where we may always find the same basic elements or patterns (self-similarity) in fractal structures.

Knowledge mapping is important in modern educational environments, because the ultimate goal is the development of reference models that are meaningful organizations of information in learners' minds. In addition, if we use significant sounds, pictures, and graphics to express ideas, learning processes are usually facilitated.

The cognition and learning related issues discussed previously, justify the need for a framework and a set of requirements to approach multimedia design for educational purposes, namely: 1) flexible access and structuring of knowledge and rich information; 2) flexible interaction with this knowledge and information; and 3) communication and interaction among participants in a learning experience. This framework could incorporate the following design ideas:

- To structure rich information and knowledge, we propose the integrated use of cognitive maps and hypermedia

- To support individual and collective interaction and manipulation of information and knowledge, we require the ability to navigate and change those structures

- To enable personal interaction and communication, we require sharing and coconstruction of both information and knowledge structures

To support interaction and communication, one must first take into account the opportunities for synchronous and asynchronous, as well as remote or co-located interaction. In this context, the time-space matrix (Table 1) summarizes the role of the different components. 
Table 1. Time Space Matrix

\begin{tabular}{|l|l|l|}
\hline Interaction & Same time & Different time \\
\hline Same space & Enhanced classroom & $\begin{array}{l}\text { Shared offline facilities, knowledge } \\
\text { and hypermedia structures }\end{array}$ \\
\hline Different space & Videoconference and chat & Shared online facilities, knowledge \\
& & and hypermedia structures \\
\hline
\end{tabular}

In the past, micro-worlds have been created to provide an entirely new framework for the learner to explore. However, today the Web can already provide numerous worlds in which one can interact. According to Cognitive Flexibility Theory (Spiro and Jengh, 1990), as learners chart their courses through the use of hypermedia material, they are able spontaneously to restructure their knowledge in many ways. For example, learners may construct knowledge artifacts initiated by the instructor, and further developed and shared in an organic, adaptive, and generative manner (Guimarães, Chambel, and Bidarra 2000). See Figure 2. 
Figure 2. Structure of a knowledge map about "Videoconferencing Facts” developed with MindManager (C)

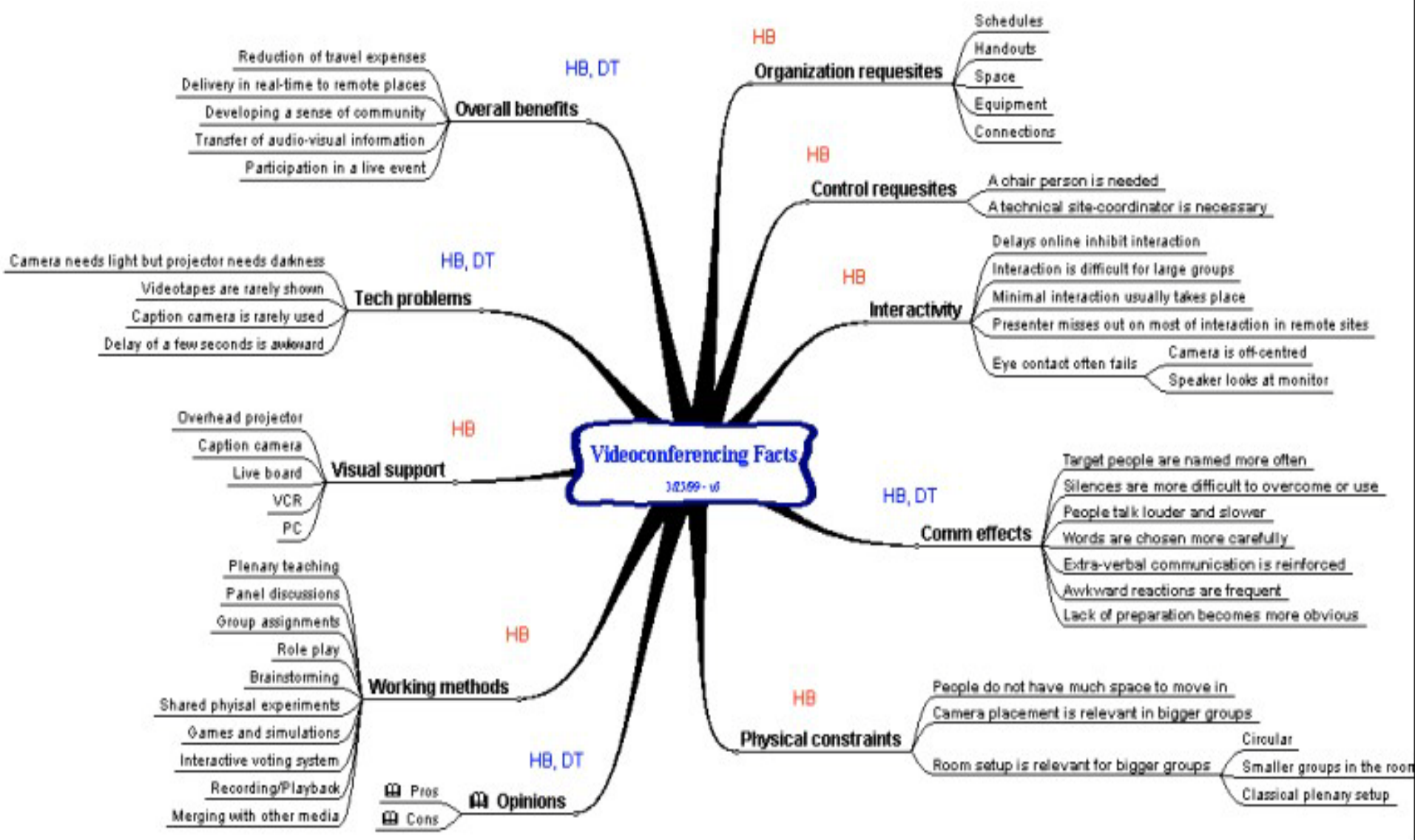

Technologies that may be used to create learning hyperscapes currently take various forms and tend to have familiar labels - for example: E-learning for Internet-based learning; T-learning for television-based learning; and M-learning for Mobile-based learning. Perhaps these technologies will have a great impact in the near future, and will change the way we conceive open and distance learning.

In an experiment conducted by Guimarães, Chambel, and Bidarra (2000) a group of students attending a Master's program on Educational Multimedia was given the task of creating fractal hyperscapes; in this case, mapping and developing of layered Web structures that reflected their interaction with knowledge with instructors and other students. The aim of this experiment was to find out how the learning process evolved as students worked together as architects of conceptual hyperspaces. Emphasis was placed at the level of students' engagement and motivation, and the final quality of the hyperscapes material. Students were given a conceptual map with the course's main themes, which they had to explore and develop further both off and online. They were encouraged to proceed from linear thinking to non-linear authoring of hyperscapes in a process comprising of four phases: 1) preparation; 2) construction; 3) interaction; and 4) presentation. 
Final assessment was based on project work following standard academic procedures. Results turned out to be promising, but required tremendous effort on the part of faculty in terms of authoring content and tutoring.

\section{Learning Management Systems}

Many corporate learning Websites are organized around tightly focused topics, containing specific technologies (ranging from chat rooms to groupware) that enable users to submit and retrieve information in a mechanical manner. In these environments we find reusable "objects," media-independent collections of information used as modular building blocks for e-Learning content. These combinations of technologies and learning methodologies usually take the form of software and/ or hardware products that suppliers tout as answers to businesses' training needs. In general, these emergent technologies do not provide the tools we need to create learning hyperscapes - at least not in the sense we have discussed so far. However, these technologies are used to attempt to solve some interesting "engineering” problems.

Current e-Learning systems tend to be based on a group of innovative software solutions, which include the learning management systems (LMSs).

Paulsen (2002) describes four main categories of systems:

- Content creation tools (CCT)

- Learning management system (LMS)

- Student management system (SMS)

- Accounting system (AS)

Figure 3.Learning Management Systems (Paulsen, 2002, p. 23 - 24)

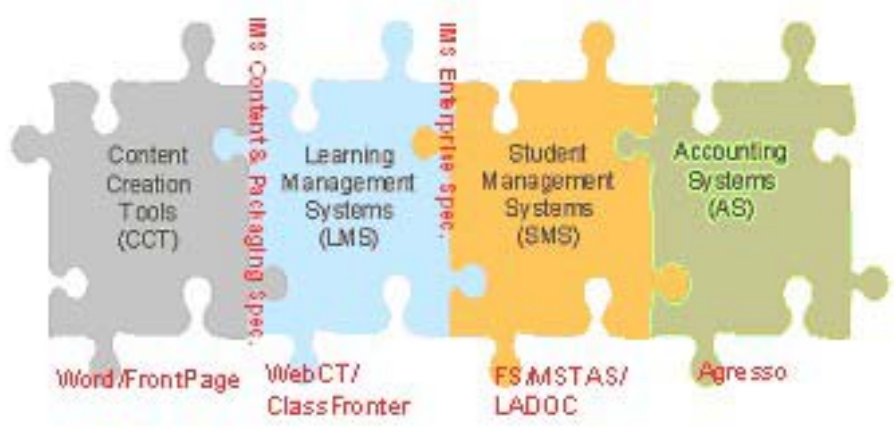

Learning management systems are intended to address a range of pedagogical and technical issues such as learning and design theory, hardware and software purchase, student support services, student assessment, student interaction, instructional strategies, security and firewalls, and staffing. The goal of this type of platform is to enable an information system that can handle effectively students, teachers, courses, and course material in an online environment. 
Paulsen (2002) explained that an online college may have to handle thousands of students, hundreds of teachers, and a large number of courses with password restricted webpages, discussion forums, distribution lists, class rosters, and student presentations. It may also have to provide administrative systems for the timely dispatch of textbooks, handling of tuition and examination fees, and organization of local examinations. Institutions that plan to offer large scale and professional online education need such a Web-based administrative system integrated with the Internet. In this technological context, it becomes clear that the main issues that still to be addressed are associated with the instructional design enabled by the system, expectations and specific needs of learners, and the role of the teacher in this new environment.

\section{Learning Objects}

Today's tendency to develop large-scale e-Learning systems, which often include proprietary learning methods, creates the need to stabilize processes based on learning objects, specifications, requirements, and standards. The ideas of content portability, granularity, and interoperability often complete the notion of systems compliant with certain norms, thereby allowing users to migrate easily from one system or software to other similar systems or software.

It is striking that terms like "standards," "requirements," "specifications," and "learning objects" currently used in e-Learning are all terms derived from "engineering." The problem, however, is that these terms represent becomes part of an "engineering process" rather than of a "pedagogical process.” Pedagogy theories appear to be positioned distantly in another domain of knowledge. Clearly, this dependency on technology and software development is driving e-Learning research into new areas, but with what effects?

An important aspect of e-Learning is that it depends upon digital technology for implementation. New and improved information technologies like databases, learning management systems (LMS), learning content management systems (LCMS), search engines, etc., are giving rise to new possibilities for storing, retrieving, and reusing information objects across systems, time, and geography (space). In his White Paper "Demystifying eLearning Standards," Singh (2001, p.4) explains these as:

Content Portability: When content has been separated from proprietary delivery systems, the organization can consolidate, organize and track their eLearning initiatives in the LMS of their choice. Because this is true for both third-party custom-content, corporations will have greater flexibility and lower switching costs.

Granularity: New specifications support learning object methodology, allowing for smaller and timelier units of information. Learning objects add “just enough" to “just-in-time” learning.

Interoperability: Application interoperability starts where different e-Learning applications can share content and tracking data. But even more exciting, these specifications open up the possibility for different types of applications to swap and access content.”

Learning objects are seen as units of information that one can manipulate. Learning objects may be organized according to a structured framework in such a way that each "information piece" operates as an independent unit, which can be defined by metadata. This idea enlarges 
possibilities for reusing, assembling and manipulating learning units, and (re)organizes them according to specific needs.

According to Olsen (2002), the fundamental idea behind this object oriented design model is that content can be split-up and put back together in new learning tracks/ courses in the same way one plays with blocks of LEGOÂ ${ }^{\circledR}$. In recent research aimed at building a semantic notation for complete units of study in e-Learning, Koper (2001) showed that a unit of study (learning object) may not be broken down to its constituent parts without losing semantic and pragmatic meaning and thus failing to attain the intended learning objectives. Such units of study may take the set form of a course, study program, workshop, tutorial, or any kind of lesson.

Unfortunately, these models always focus on learning with bits and pieces of information (i.e., objects), and overlook the didactic or pedagogical model behind it. Learning perspectives that take into consideration cognitive variables - e.g., the learners' sphere of interests - must be taken into account.

\section{Conclusion}

Within a context of widespread multimedia content, following the emergence of massive information resources, there is a need for need for more powerful and effective learner-centered tools, capable of handling all kinds of design configurations and learning objects. Therefore we must ask: How do we address the cognitive needs of learners using new information technologies like databases, Learning Management Systems, and Learning Content Management Systems?

A first recommendation is to consider a model sustaining the acceptance of information technology by the learner, namely, to find out:

- What do users want an e-Learning system to look like? And what functionality should be included? (Can we proactively address their different learning styles?)

- To what degree do individuals believe that using a particular e-Learning system will enhance their global performance? (Can we show the benefits outweigh the costs?)

- What amount of mental or physical effort do individuals need to make in order to derive tangible benefits from the e-Learning system? (Can we inform learners through straightforward tutorials?)

Secondly, knowledge construction that accompanies an evolutionary process of self-development often yields unpredictable outcomes. Implicit suggestions therefore are to adopt pro-active learning strategies; foster collaboration with peers and other students; and adopt a bold perspective concerning the problems to solve. For instance, "chaotic" elements that enter the processes in creative activities (e.g., generation of new ideas) must be managed according to each learner's path and progression in order to arrive at meaningful results.

Greater flexibility does not necessarily call for application of less professional approaches. In fact, the exercise of more "authority," which is usually attributed to the teacher or organization, is 
no longer desirable. Nevertheless, looking at the latest learning platforms, we find that these cognitive variables and pedagogical processes are rarely taken into consideration, and sometimes they are confused with the mere use of "diversified" hypermedia resources by learners. What remains is the idea that pedagogy vs. technology is a problematic contest that needs to be clarified by further research. We do not know for sure how learning takes place in the realm of today's Web hyperscapes and digital technologies, but we do know a great deal about human cognition.

In conclusion, by covering both old and new conceptual spaces we have examined some emerging issues in e-Learning. We have described the need for a bridge between cognitive issues and digital technology solutions, and new ways for instructional designers to create materials. We have also suggested ways to engage learners in reflective practice and critical thinking with mind mapping. Clearly, much more work and research needs to be done, but perhaps Salomon (2000) pointed the way forward when he said: "Let technology show us what can be done, and let educational considerations determine what will be done in actuality." 


\section{References}

Buzan, T. (1995). The MindMap Book. 2nd Edition. London: BBC Books.

Gaines, B. R., and Shaw, M. L. G. (1995). Concept Maps as Hypermedia Components. Retrieved February 13, 1998 from: http://ksi.cpsc.ucalgary.ca/articles/ConceptMaps/CMa.html

Guimarães, N., Chambel, T., and Bidarra, J. (2000). From Cognitive Maps to Hypervideo: Supporting Flexible and Rich Learner-Centred Environments. Interactive Multimedia Electronic Journal of Computer-Enhanced Learning, 2(3). Wake Forest University. Retrieved July 20, 2003 from: http://imej.wfu.edu/articles/2000/2/03/index.asp

Hay, K., Guzdial, M., Jackson, S., Boyle, R., and Soloway, E. (1994). Students as Multimedia Composers. Computers \& Education, 23, $301-317$.

Jung, C. G. (1960). The Structure and Dynamics of the Psyche: Collected works, 8. Princeton, NJ.: Princeton University Press.

Kahneman, D., Slovic,P., and Tversky, A. (1982). Judgement Under Uncertainty: Heuristics and biases. Cambridge, UK.: Cambridge University Press.

Kolb, D. A. (1984). Experiential Learning: Experience as the source of learning and development. Englewood, CA.: Prentice Hall.

Koper, R. (2001). Modeling Units of Study from a Pedagogical Perspective. Technical Report. Open University of the Netherlands.

Olsen, G. S. (2002). Stand Ready? Emerging e-Learning standards in a pedagogical perspective. In Web Education Systems in Europe. FernUniversitat, Germany: ZIFF Papiere 118.

Paulsen, M. F. (2000). Online Education: An International Analysis of Web-based Education and Strategic Recommendations for Decision Makers. EU: CISAER Report.

Paulsen, M. F. (2002). Online Education Systems: Definition of terms. In Web Education Systems in Europe. FernUniversitatm Germany: ZIFF Papiere 118.

Rogers, Y., and Scaife, M. (1997). How can Interactive Multimedia Facilitate Learning? Brighton, UK.: University of Sussex. Retrieved March 5, 1998 from: http://www.cogs.susx.ac.uk/users/IMMI.html

Salomon, G. (2000). It's Not Just the Tool, But the Educational Rationale that Counts. Keynote speech. ED-MEDIA 2000: Montreal, June.

Singh, H. (2001). Demystifying eLearning Standards. Centra. Retrieved September 12, 2003 from: http://www.e-learningsite.com/download/white/stand-cen.pdf 
Spiro, R. J., and Jengh, J. (1990). Cognitive Flexibility and Hypertext: Theory and Technology for the Non-linear and Multidimensional Traversal of Complex Subject Matter. In D. Nix and R. Spiro (Eds.) Cognition, Education and Multimedia. Hillsdale, NJ.: Erlbaum.

Uys, P. (1998). The hydi Educational New Media Centre: Findings in distributed on-line education. Retrieved September 3, 2003 from: http://www.globeonline.com/philip.uys/www.globe-online.com,philip.uys,kmi1998.htm

Whalley, P. (1997). Dynamic Images in Educational Multimedia. Milton Keynes: Institute of Educational Technology. The Open University, UK.

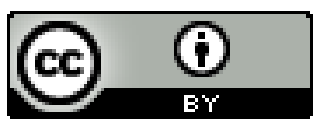

